\title{
Country-Specific Prevalence and Incidence of Youth-Onset Type 2 Diabetes: A Narrative Literature Review
}

\author{
Jane L. Lynch ${ }^{a} \quad$ Margarita Barrientos-Pérez $^{b} \quad$ Mona Hafez $^{c}$ \\ Muhammad Yazid Jalaludin ${ }^{d}$ Margarita Kovarenko ${ }^{e}$ Paturi Vishnupriya Rao ${ }^{f}$ \\ Daniel Weghuberg \\ aUniversity of Texas Health Science Center San Antonio, San Antonio, TX, USA; b Pediatric Endocrinology, Angeles \\ Hospital of Puebla, Puebla, Mexico; ' Diabetes and Endocrinology Unit, Department of Paediatrics, Cairo University, \\ Cairo, Egypt; ${ }^{d}$ Department of Paediatrics, Faculty of Medicine, University of Malaya, Kuala Lumpur, Malaysia; \\ eNovosibirsk Medical University, Novosibirsk, Russia; 'Diabetes Research Society, Hyderabad, India; ${ }^{9}$ Department of \\ Pediatrics, Paracelsus Medical School, Salzburg, Austria
}

\section{Keywords}

Prevalence - Incidence $\cdot$ Diabetes mellitus type $2 \cdot$ Child . Adolescent

\begin{abstract}
Background: With increased awareness of type 2 diabetes (T2D) in children and adolescents, an overview of countryspecific differences in epidemiology data is needed to develop a global picture of the disease development. Summary: This study examined country-specific prevalence and incidence data of youth-onset T2D published between 2008 and 2019, and searched for national guidelines to expand the understanding of country-specific similarities and differences. Of the 1,190 articles and 17 congress abstracts identified, 58 were included in this review. Our search found the highest reported prevalence rates of youth-onset T2D in China (520 cases/100,000 people) and the USA (212 cases/100,000) and lowest in Denmark (0.6 cases/100,000) and Ireland (1.2 cases/100,000). However, the highest incidence rates were reported in Taiwan (63 cases/100,000) and the UK (33.2 cases/100,000), with the lowest in Fiji (0.43 cas-
\end{abstract}

karger@karger.com www.karger.com/anm

Karger $\stackrel{\text { ' }}{5}$

GOPEN ACCESS
(C) 2020 The Author(s)

Published by S. Karger AG, Basel

This is an Open Access article licensed under the Creative Commons Attribution-NonCommercial-4.0 International License (CC BY-NC) (http://www.karger.com/Services/OpenAccessLicense), applicable to the online version of the article only. Usage and distribution for commercial purposes requires written permission. es $/ 100,000)$ and Austria $(0.6$ cases $/ 100,000)$. These differences in epidemiology data may be partly explained by variations in the diagnostic criteria used within studies, screening recommendations within national guidelines and race/ethnicity within countries. Key Messages: Our study suggests that published country-specific epidemiology data for youth-onset T2D are varied and scant, and often with reporting inconsistencies. Finding optimal diagnostic criteria and screening strategies for this disease should be of high interest to every country. Trial Registration: Not applicable.

(c) 2020 The Author(s)

Published by S. Karger AG, Basel

\section{Introduction}

With a current estimated global healthcare cost of USD 760 billion in diabetes treatment and complications, and an estimated 51\% increase in the number of people affected by diabetes by 2045 [1], the growing pandemic of diabetes poses a serious global challenge. In adults, type 2 diabetes (T2D) accounts for about $90 \%$ of all diabetes cases [1] and, until the early 1990s, it was considered a pre-

Jane L. Lynch

Division of Endocrinology and Diabetes, University of Texas Health Science Center San Antonio 7703 Floyd Curl Dr.

San Antonio, TX 78229 (USA)

LYNCHJ2@uthscsa.edu 
dominantly adult disease [2]. However, the last few decades have witnessed a trend of increasing cases of T2D in children, particularly in North America, mirroring the increasing rates of obesity [2]. Following the current incidence rates, it is projected that, by 2050 , there may be a 4 -fold increase in the prevalence of youth-onset T2D [3].

Compared with the breadth of knowledge on adult T2D, global epidemiology data on youth-onset T2D appear quite limited [1]. Scarcity of global data in youthonset T2D may be attributable to the varied clinical presentation of T2D in children and adolescents $[4,5]$, the barriers preventing access to appropriate care and the high cost of appropriate diagnostic testing [6]. In the majority of cases, diabetes is often clinically diagnosed when children and adolescents present with symptoms such as polyuria, polydipsia, and weight loss [5]. However, distinguishing between type 1 diabetes (T1D) and T2D in children and adolescents can be problematic, as both types of diabetes may present with similar traits $[7,8]$. Recently, overweight and obesity have been frequently identified in children with T1D [9], whereas patients with T2D can present with significant ketosis and initial metabolic values suggestive of T1D [10]. Furthermore, a few recent studies suggest that the standard glycated hemoglobin $\left(\mathrm{HbA}_{1 \mathrm{c}}\right)$ test used to diagnose diabetes in the adult population may not be the most appropriate diagnostic tool in children and adolescents [11, 12], especially among certain ethnic groups [13]. Even with these difficulties in diagnosing youth-onset T2D, several studies have published epidemiology data, which may allow a global picture of this disease to be developed. To understand country-specific similarities and differences in the epidemiology of youth-onset T2D, we performed a literature search of studies in this field and examined the data.

\section{Methods}

Data Sources and Searches

We performed a literature search of the electronic database PubMed, using the search parameters described in the online suppl. Table 1 (see www.karger.com/doi/10.1159/000510499 for all online suppl. material) for articles published between January 1, 2008 , and October 17, 2019. In summary, initial searches were performed relating to "pediatric" and "T2D," and then these searches were combined and filtered with a list of search criteria relating to "epidemiology." For the purposes of this review, non-English publications were excluded. To capture country-specific data available in abstracts only and unlikely to be in PubMed, we performed similar searches of published abstract books for the last 3 meetings of the Latin American Pediatric Endocrinology Society (SLEP: 3 abstract books available) and the Asia Pacific Pediatric Endocrine
Society (APPES: 3 abstract books available). As all data used within this review came from published source, no ethics approval was required.

\section{Study Selection}

We reviewed the search results and excluded articles deemed irrelevant, such as those only describing T1D or gestational diabetes in adults and that may have mentioned T2D in passing but did not include sufficient details. For the purposes of this review, the pediatric population was defined as those $\leq 20$ years of age; any studies focused on older populations were not included. We also excluded reviews, individual case studies, editorials, and studies that did not measure the prevalence or incidence of youth-onset T2D.

\section{Data Extraction and Figure Generation}

The full articles or abstracts were analyzed for data on the epidemiology of youth-onset T2D. If numerical data were present, the article or abstract was included in this review. Where more than one study reported prevalence/incidence data for the same country, the most recent data were used to generate figures on countryspecific prevalence and incidence of youth-onset T2D across the globe.

\section{National Guidelines on Diagnosis of Youth-Onset T2D}

To enable a greater level of understanding of youth-onset T2D epidemiology, we searched for national guidelines on this topic. We used several strategies to identify the data sources used in this analysis. We performed a search using PubMed and the National Guideline Clearinghouse for articles on youth-onset T2D and guidelines. We also performed a general web search using the Google search engine. For all the references identified by our main search that reported epidemiological data, we checked their methods and reference lists to determine if they used national guidelines to diagnose T2D. In addition, each author provided a translated copy of the official national guidelines for the diagnosis of youthonset T2D in their own countries, where available.

\section{Results}

Our search criteria identified 1,190 articles and 17 congress abstracts, of which 83 were fully assessed for eligibility, and 58 were included in this review (online suppl. Fig. $1)$. Details about the studies included in this review are summarized in the online suppl. Table 2 . Of the 58 publications included in this review, 38 measured prevalence, 28 measured incidence, and 8 measured both. Not all studies were completed at a country-level, with 11 focusing on a single study center. The majority of studies included in this analysis measured prevalence for some of the years between 2000 and 2016 .

\section{Country-Specific Prevalence of T2D in Children and Adolescents}

Within our search, we identified 21 publications reporting prevalence data of $\mathrm{T} 2 \mathrm{D}$ in children and adolescents on 


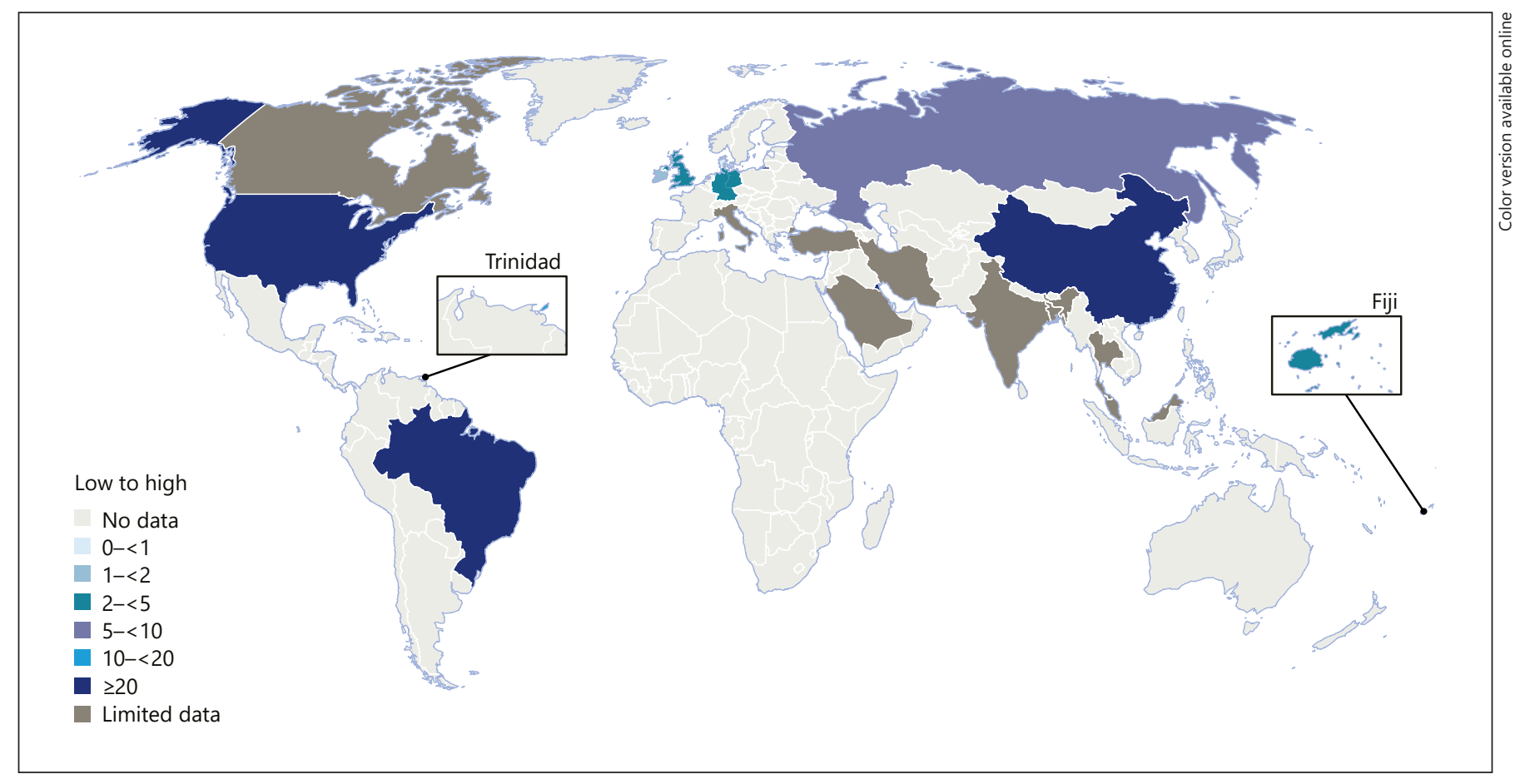

Fig. 1. Country-specific prevalence of T2D in children and adolescents. Prevalence reported as number of cases/100,000 people (for references and details of studies, see online suppl. Table 2). Limited data refer to studies reporting data for 1 single study center only, or combined T1D and T2D prevalence. T1D, type 1 diabetes; T2D, type 2 diabetes.

a country-specific level for 12 different countries (online suppl. Table 2; Fig. 1). A further 7 countries had other types of prevalence data available (e.g., data limited to a single study center or combined T1D and T2D prevalence), making it difficult to make direct comparisons (Fig. 1).

Among those countries reporting country-specific prevalence data, the highest prevalence of youth-onset T2D was found in China (520 cases/100,000 people) [14] and the USA (212 cases/100,000 people) [15], while the lowest prevalence was found in Denmark (0.6 cases/100,000 people) [16] and Ireland (1.2 cases/100,000 people) [17]. In studies reporting data analyzed by ethnic groups, a higher prevalence of youth-onset T2D was observed in ethnic minorities (African American, Aboriginal, Hispanic, Asian, and Pacific Island descendants), compared with Caucasian and non-Hispanic White children and adolescents ([18-21]; see online suppl. Table 2).

\section{Country-Specific Incidence of T2D in Children and Adolescents}

Our literature search provided country-specific incidence data for 14 countries (online suppl. Table 2; Fig. 2).
Three additional countries only reported data for combined T1D and T2D or relating to a single study center (Fig. 2) [22-24].

Highest incidence rates were observed in Taiwan (63 cases/100,000 people) [25] and the UK (33.2 cases/100,000 people) [26]. Lowest incidence rates were observed in Fiji ( 0.43 cases $/ 100,000$ people) [27] and Austria (less than 0.6 cases $/ 100,000$ people) [28]. Of the publications reporting country-specific incidence of youth-onset T2D, $11 \mathrm{com}$ pared the incidence among ethnic groups, reporting higher figures for ethnic minorities such as African American, Aboriginal, Hispanic, Asian, and Pacific Island descendants, compared with non-Hispanic White ([19-21]; see online suppl. Table 2).

\section{National Guidelines for the Diagnosis of Pediatric \\ T2D}

Our analysis identified a number of countries reporting national guidelines for the diagnosis of youth-onset T2D (online suppl. Table 3), with some of these based on the American Diabetes Association guidelines (produced annually; 2019 version [10]), or international guidelines pro- 


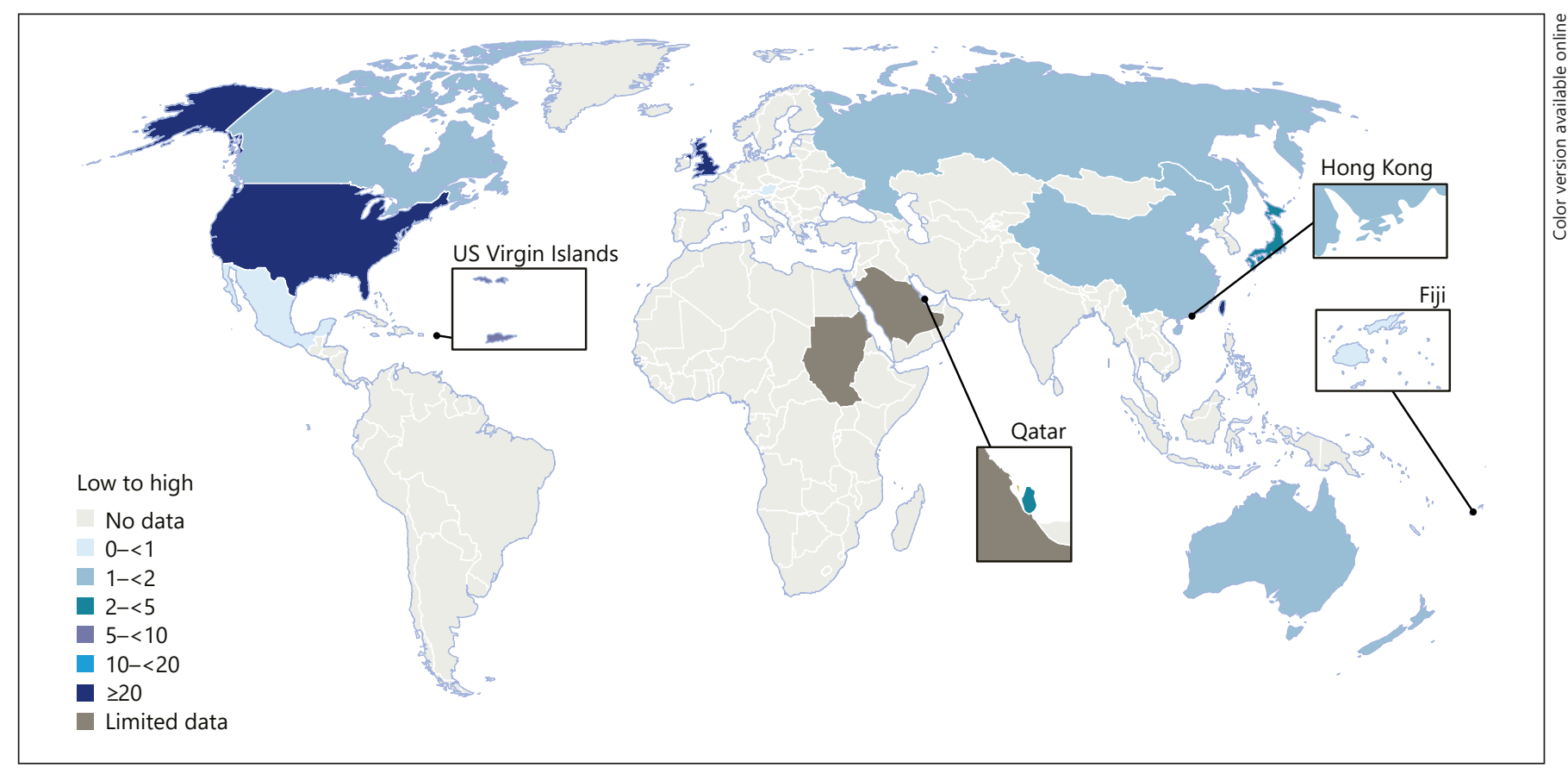

Fig. 2. Country-specific incidence of $T 2 D$ in children and adolescents. Incidence reported as number of cases/100,000 people (for references and details of studies, see online suppl. Table 2). Limited data refer to studies reporting data for 1 single study center only, or combined T1D and T2D prevalence. T1D, type 1 diabetes; T2D, type 2 diabetes.

vided by the International Society for Pediatric and Adolescent Diabetes (produced biannually; 2018 version [12, 29]) and the World Health Organization (WHO) [30].

Of the 2 main global guidelines, only the International Society for Pediatric and Adolescent Diabetes recommends specific criteria that are tailored to children and adolescents $[12,29]$. Prior to 2019, guidelines from the WHO did not specify criteria for diagnosing pediatric T2D or for distinguishing between T1D and T2D [30, 31]. Therefore, all of the included studies based on the WHO guidelines used diagnostic criteria that were devised for the adult population. In 2019, however, the WHO released a new document on the classification of diabetes, including the use of age at diagnosis as a guide to subtyping diabetes [32], which may be used in future studies or guideline updates.

Overall, national guidelines differ from each other in tests used to diagnose diabetes in children and adolescents, with the majority recommending fasting plasma glucose levels or oral glucose tolerance test. In most countries, measurement of antibody titers is ultimately required to differentiate T1D from T2D (online suppl. Table 3).
In 2018, Bhatt et al. [33] completed a comprehensive systematic quality review of clinical practice guidelines for the management of T2D in children and adolescents aged 2-18 years. Of the 21 unique published guidelines identified, they found only 5 that were specific to pediatric populations. A common theme among the guidelines was that $\mathrm{HbA}_{1 \mathrm{c}}$ should not be used alone for the diagnosis of pediatric patients, and most recommended screening every 2 years via fasting or random glucose tests when in the presence of certain risk factors (obesity, family history, high-risk race/ethnicity, and signs of insulin resistance). They also found that two-thirds of the guidelines were moderate to low in quality, which was particularly evident within the guideline development methodology [33].

\section{Discussion}

In our literature search on country-specific prevalence and incidence of youth-onset T2D, we found that some of the more economically developed countries, such as the USA and China, have the highest reported rates 
worldwide. The analysis also highlighted that data for T2D in children and adolescents are still scarce across the globe. Finally, we identified that only a few countries have easily accessible national guidelines for the diagnosis of youth-onset T2D.

Similar to our findings, $\mathrm{Ng}$ et al. [34] demonstrated, when analyzing data from all countries, that childhood obesity is greatest in the USA. They also measured the prevalence of children with overweight and obesity since 1980 and found that it has increased substantially over the last 30 years. The rapid increase in children and adolescents with obesity is linked to the increase in youth-onset T2D, and similar trends are evident in adults [1]. The direct, causative link between these conditions is outside the scope of this review, but it is interesting to note that obesity is one of the predominant features in children and adolescents with T2D, being observed in almost $85 \%$ of the cases $[4,35]$. However, while obesity is often observed in children and adolescents with T2D from Western regions, such as the USA and Europe [4], 30-50\% of youthonset T2D cases in Eastern countries, such as Japan [36], India [37], and Taiwan [38], have normal weight. In addition, southern European countries such as Italy and Spain are facing some of the world's highest obesity rates, but, conversely, their T2D prevalence rates are low [3941]. These somewhat contrasting results suggest that the link between obesity and T2D is complex and often involves interindividual differences in pathogenesis.

Our analysis has also highlighted highest rates of youth-onset T2D in ethnic minorities, as previously reported [6]. Higher prevalence and incidence of T2D have been observed in children and adolescents belonging to the African American, Aboriginal, Hispanic, and Asian and Pacific Islander ethnicities, compared with Caucasian and European ethnic groups ([18-21, 42]; see online suppl. Table 2). In the 10-year follow-up survey of a crosssectional study, Neu et al. [43] found that the prevalence of youth-onset T2D in South Germany remained unchanged over the past 10 years and that the majority of youth-onset T2D cases were part of specific ethnic minorities. This suggested that the low prevalence of T2D in Central Europe is likely due to a considerably lower number of youths belonging to ethnic minorities compared with North America. In addition, a recent study observing the prevalence and incidence of youth-onset T2D in Fiji reported low incidence rates, a surprising result considering that Pacific Islanders living in Western countries are often reported to be at high risk for T2D [27, 44]. However, the same study reported a striking difference in incidence of youth-onset T2D depending on whether the

Country-Specific Pediatric Type 2

Diabetes Epidemiology Data patients were native Fijians or Indo-Fijians, or Fijians of European descent, thus corroborating the impact of ethnicity in youth-onset T2D [27]. These differences in youth-onset T2D prevalence and incidence across ethnic minorities are very important to consider in both clinical practice and government strategies, especially in modern society as countries are progressively becoming more multi-ethnic [45].

One of the included studies, by Jabar et al. [46], reports remarkably high rates of T2D (11.9\% of the total cohort; $23.3 \%$ of those aged $\geq 10$ years and $44.9 \%$ aged $\geq 16$ years) in First Nation heritage (Canada) children of mothers with youth-onset ( $<18$ years) T2D. Of interest, it is known that many Canadian First Nation youth have a unique hepatocyte nuclear factor 1-alpha (HNF-1 $\alpha$ G319S) polymorphism [46, 47], which has been associated with a form of maturity-onset diabetes of the young, which mimics T2D. The results, therefore, highlight that this form of non-autoimmune diabetes could impact overall estimates of T2D in children and adolescents in specific regions where forms of maturity-onset diabetes of the young are prevalent.

When comparing prevalence and incidence levels of youth-onset T2D across countries, our analysis highlighted a common issue: that is, the lack of universal diagnostic criteria for T2D in children and adolescents, which may be a consequence of lack of available resources for high-cost diagnostic expenses. The studies identified in our search used a variety of criteria to diagnose youth-onset T2D, ranging from simple physician diagnosis to full antibody titer tests $[18,39]$. With such a range of criteria used, it is difficult to determine if any of the reported data are directly comparable and whether the true disease burden of pediatric T2D can be fully understood.

The lack of a consistent diagnostic method for youthonset T2D was also reflected in the international and national guidelines. National guidelines differ across countries, with some of these using the same criteria to diagnose diabetes in adults and youths [48]. Additionally, not all countries have national guidelines allowing differentiation between T1D and T2D, an important issue in this field. While several developed countries have their own screening recommendations in place $[10,33$, 48-56], this is not the case for all countries. In many cases where national guidelines are missing, global guidelines or other national guidelines, such as those from the American Diabetes Association, are followed instead. Other countries have responded to the increase in youth-onset T2D through establishing a diabetes 
register to monitor how the disease will change over time [57], and a growing number of studies recognize the need for early and accurate diabetes screening [7, 58]. The presence of a screening program is likely to increase the diagnostic rate, and hence the incidence of youth-onset T2D, which may explain some of the variation in the reported epidemiological data in this disease. More recently, similar findings were evident in the Bhatt et al. [33] systematic review of current clinical practice guidelines for pediatric $\mathrm{T} 2 \mathrm{D}$, which highlighted the importance of access to up-to-date high-quality guidelines for the appropriate diagnosis and management of youth-onset T2D and suggested that significant improvements are needed in the methodology of development and quality of reporting.

This study has important limitations. First, prevalence and incidence data included in this review are only for countries reporting the data in journals indexed in PubMed. While we attempted to compensate for this through searching SLEP and APPES recent congresses, it may also be that there are studies in journals not indexed in PubMed. Second, different studies used different age ranges to describe the pediatric population. Although we included results for patients aged 0-20 years, some of the studies only captured data for patients up to 16 years of age, and others excluded children less than 6 years of age. Third, studies reported in this review ran their analyses in different years; therefore, the regional prevalence and incidence data shown do not necessarily describe the current status of prevalence and incidence of T2D in children and adolescents, but nevertheless show a trend across several countries.

For future studies, we recognize emerging evidence regarding the role that socioeconomic status plays in the development of T2D, as well as other non-communicable diseases in pediatric populations, invites further consideration $[59,60]$. At present, the defining factors of socioeconomic status (including income, education, and employment) vary across publications, making direct comparisons between findings challenging. A comprehensive investigation utilizing standardized definitions may help to further our knowledge on this factor within youth-onset T2D and its underlying pathways.

\section{Conclusion}

This review highlights large differences in the reported prevalence and incidence of youth-onset T2D between and within countries, with the majority of studies reporting data mainly for the more economically developed countries. We hypothesize that these discrepancies could be largely related to differences in national screening programs and diagnostic criteria used in some studies, and possibly due to inherent ethnic differences in pediatric populations in others. The reported figures on country-specific youth-onset T2D may underestimate its true occurrence; therefore, finding optimal screening strategies and treatment options for diabetes in children and adolescents is highly likely to be of national interest to every country. Data on prevalence and incidence rates are essential to understand the current and potential future numbers of youth-onset $\mathrm{T} 2 \mathrm{D}$ and to better inform the planning of required healthcare.

\section{Acknowledgements}

Medical writing and editing support were provided by Ugo Battaglia, PhD, and Izabel James, MBBS, of Watermeadow Medical, an Ashfield Co., part of UDG Healthcare plc, funded by Novo Nordisk A/S. The manuscript was reviewed for medical accuracy by Divyalasya TVS, on behalf of Novo Nordisk. The authors are part of the Novo Nordisk Pediatric T2D Global Expert Panel. Other members of this group discussed initial ideas for this review with the authors, but did not contribute to its development. These other expert panel members are Timothy Barrett (University of Birmingham), Naim Shehadeh (Rambam Health Care Campus), and Serap Turan (Marmara University School of Medicine).

\section{Conflict of Interest Statement}

All authors are members of the Novo Nordisk Pediatric Type 2 Diabetes Global Expert Panel and as such have received honoraria from Novo Nordisk. In addition, the authors declare the following: J.L. received fees from Novo Nordisk, NIH, and Daiichi Sankyo as a principal investigator and for consultancy work. M.B.-P. received fees from Novo Nordisk, Sanofi, Eli Lilly, and Opko as a principal investigator and from Pfizer, Abbott, Novo Nordisk, Sandoz, and Eli Lilly for consultancy work and lectures. M.H. received fees from Novo Nordisk for consultancy work. M.Y.J. received research grants from the Ministry of Health Malaysia, Newton-Ungku Omar Research Fund, and University Malaya. He also received honoraria from Nestle Nutrition Institute and Abbott Nutrition for consultation and lectures and from Novo Nordisk and Merck Sharp \& Dohme as an expert panel reviewer. M.K. received fees from Novo Nordisk for consultancy work. P.R. received clinical trial payments from Novo Nordisk, Sanofi, Eli Lilly, IPCA laboratories, Hetero Pharma, Allergan, Parexel, and IQVIA; honorarium from the Indian Council of Medical Research; and employment benefits from DiabetOmics. D.W. declares no other conflicts of interest. 


\section{Funding Sources}

Novo Nordisk funded the medical writing support for this review. It had no role in the design of the review or in the collection, analysis and interpretation of the data. A medical accuracy review of the manuscript was performed by Novo Nordisk.

\section{Author Contributions}

All authors conceived, reviewed, and approved this review. J.L.L., M.B.-P., M.H., M.Y.J., M.K., P.V.R., and D.W. had input into the search terms used for the literature search. J.L.L., M.B.-P., M.H., M.Y.J., M.K., P.V.R., and D.W. screened the results obtained from the literature search. J.L.L., M.B.-P., M.H., M.Y.J., M.K., P.V.R., and D.W. also reviewed each draft and then read and approved the final manuscript.

\section{References}

1 International Diabetes Federation. IDF Diabetes Atlas. 9th ed. 2019. Available from: https://www.diabetesatlas.org/en/resources/.

2 Arslanian S. Type 2 diabetes in children: clinical aspects and risk factors. Horm Res. 2002; 57(Suppl 1):19-28.

3 Imperatore G, Boyle JP, Thompson TJ, Case D, Dabelea D, Hamman RF, et al. Projections of type 1 and type 2 diabetes burden in the U.S. population aged $<20$ years through 2050 : dynamic modeling of incidence, mortality, and population growth. Diabetes Care. 2012; 35(12):2515-20.

4 Rosenbloom AL, Silverstein JH, Amemiya S, Zeitler P, Klingensmith GJ. ISPAD Clinical Practice Consensus Guidelines 2006-2007. Type 2 diabetes mellitus in the child and adolescent. Pediatr Diabetes. 2008;9(5):512-26.

5 Pinhas-Hamiel O, Zeitler P. A weighty problem: diagnosis and treatment of type 2 diabetes in adolescents. Diabetes Spectr. 1997; 10(4):292-8.

6 Reinehr T. Type 2 diabetes mellitus in children and adolescents. World J Diabetes. 2013; $4(6): 270-81$.

7 Rodbard HW. Diabetes screening, diagnosis, and therapy in pediatric patients with type 2 diabetes. Medscape J Med. 2008;10(8):184; quiz 184.

8 Fagot-Campagna A, Pettitt DJ, Engelgau MM, Burrows NR, Geiss LS, Valdez R, et al. Type 2 diabetes among North children and adolescents: an epidemiologic review and a public health perspective. J Pediatr. 2000; 136(5):664-72.

9 DuBose SN, Hermann JM, Tamborlane WV, Beck RW, Dost A, DiMeglio LA, et al. Obesity in youth with type 1 diabetes in Germany, Austria, and the United States. J Pediatr. 2015; 167(3):627.

10 American Diabetes Association. 13. Children and adolescents: standards of medical care in diabetes-2019. Diabetes Care. 2019;42(Suppl 1):S148-64.

11 Kapadia CR. Are the ADA hemoglobin A(1c) criteria relevant for the diagnosis of type 2 diabetes in youth? Curr Diab Rep. 2013;13(1):51-5.

12 Mayer-Davis EJ, Kahkoska AR, Jefferies C, Dabelea D, Balde N, Gong CX, et al. ISPAD clinical practice consensus guidelines 2018: definition, epidemiology, and classification of diabetes in children and adolescents. Pediatr Diabetes. 2018;19(Suppl 27):7-19.
13 Kamps JL, Hempe JM, Chalew SA. Racial disparity in A1C independent of mean blood glucose in children with type 1 diabetes. Diabetes Care. 2010;33(5):1025-7.

14 Chi X, Yu D, Ju L, Zhang J, Zhao L. [Prevalence of diabetes and change among 7 to 17 years old children and adolescents in China in 2002-2012]. Wei Sheng Yan Jiu. 2018;47(5): 705-15.

15 Chen Y, Wang T, Liu X, Shankar RR. Prevalence of type 1 and type 2 diabetes among US pediatric population in the marketScan multistate database, 2002 to 2016. Pediatr Diabetes. 2019;20(5):523-9.

16 Oester IM, Kloppenborg JT, Olsen BS, Johannesen J. Type 2 diabetes mellitus in Danish children and adolescents in 2014. Pediatr Diabetes. 2016;17(5):368-73.

17 O'Dea MI, O'Connell SM, O'Grady MJ. Prevalence and characteristics of paediatric type 2 diabetes in the Republic of Ireland. Diabet Med. 2017;34(11):1603-7.

18 Khanolkar AR, Amin R, Taylor-Robinson D, Viner R, Warner J, Stephenson T. Ethnic minorities are at greater risk for childhood-onset type 2 diabetes and poorer glycemic control in England and Wales. J Adolesc Health. 2016; 59(3):354-61.

19 Mayer-Davis EJ, Beyer J, Bell RA, Dabelea D, D’Agostino R Jr, Imperatore G, et al. Diabetes in African American youth: prevalence, incidence, and clinical characteristics: the SEARCH for Diabetes in Youth Study. Diabetes Care. 2009;32(Suppl 2):S112-22.

20 Liu LL, Yi JP, Beyer J, Mayer-Davis EJ, Dolan LM, Dabelea DM, et al. Type 1 and Type 2 diabetes in Asian and Pacific Islander U.S. youth: the search for Diabetes in Youth Study. Diabetes Care. 2009;32(Suppl 2):S133-40.

21 Dabelea D, DeGroat J, Sorrelman C, Glass M, Percy CA, Avery C, et al. Diabetes in Navajo youth: prevalence, incidence, and clinical characteristics: the search for Diabetes in Youth Study. Diabetes Care. 2009;32(Suppl 2):S141-7.

22 Al-Rubeaan K. National surveillance for type 1 , type 2 diabetes and prediabetes among children and adolescents: a population-based study (SAUDI-DM). J Epidemiol Community Health. 2015;69(11):1045-51.
23 Sjardin N, Reed P, Albert B, Mouat F, Carter PJ, Hofman P, et al. Increasing incidence of type 2 diabetes in New Zealand children. J Paediatr Child Health. 2018;54(9):100510.

24 Osman HA, Elsadek N, Abdullah MA. Type 2 diabetes in Sudanese children and adolescents. Sudan J Paediatr. 2013;13(2):17-23.

25 Chen MH, Lan WH, Hsu JW, Huang KL, Su $\mathrm{TP}, \mathrm{Li}$ CT, et al. Risk of developing type $2 \mathrm{dia}-$ betes in adolescents and young adults with autism spectrum disorder: a nationwide longitudinal study. Diabetes Care. 2016;39(5):78893.

26 Shield JP, Lynn R, Wan KC, Haines L, Barrett TG. Management and 1 year outcome for UK children with type 2 diabetes. Arch Dis Child. 2009;94(3):206-9.

27 Ogle GD, Morrison MK, Silink M, Taito RS. Incidence and prevalence of diabetes in children aged. Pediatr Diabetes. 2016;17(3):2226.

28 Schober E, Waldhoer T, Rami B, Hofer S. Incidence and time trend of type 1 and type 2 diabetes in Austrian children 1999-2007. J Pediatr. 2009;155(2):190.

29 Zeitler P, Arslanian S, Fu J, Pinhas-Hamiel O, Reinehr T, Tandon N, et al. ISPAD clinical practice consensus guidelines 2018: type 2 diabetes mellitus in youth. Pediatr Diabetes. 2018;19(Suppl 27):28-46.

30 World Health Organization. Definition and diagnosis of diabetes mellitus and intermediate hyperglycaemia: report of a WHO/IDF consultation. 2006. Available from: http:// www.who.int/diabetes/publications/Definition $\% 20$ and $\% 20$ diagnosis $\% 20$ of\%20diabetes_new.pdf [Accessed 2018 Apr 17].

31 World Health Organization. Global report on diabetes. 2016. Available from: http://www. who.int/diabetes/global-report/en/ [Accessed 2018 Apr 17].

32 World Health Organization. Classification of diabetes mellitus. 2019. Available from: https: //www.who.int/publications-detail/classification-of-diabetes-mellitus [Accessed 2019 Nov 12].

33 Bhatt M, Nahari A, Wang PW, Kearsley E, Falzone N, Chen S, et al. The quality of clinical practice guidelines for management of pediatric type 2 diabetes mellitus: a systematic review using the AGREE II instrument. Syst Rev. 2018;7(1):193. 
34 Ng M, Fleming T, Robinson M, Thomson B, Graetz N, Margono C, et al. Global, regional and national prevalence of overweight and obesity in children and adults 1980-2013: a systematic analysis. Lancet. 2014;384(9945): 766-81.

35 American Diabetes Association. Type 2 diabetes in children and adolescents. American Diabetes Association. Diabetes Care. 2000; 23(3):381-9.

36 Sugihara S, Sasaki N, Amemiya S, Kohno H, Tanaka T, Matsuura N. Analysis of weight at birth and at diagnosis of childhood-onset type 2 diabetes mellitus in Japan. Pediatr Diabetes. 2008;9(4 Pt 1):285-90.

37 Ramachandran A, Snehalatha C, Satyavani K, Sivasankari S, Vijay V. Type 2 Diabetes in Asian-Indian Urban Children. Diabetes Care. 2003;26(4):1022-5.

38 Wei JN, Sung FC, Li CY, Chang CH, Lin RS, Lin CC, et al. Low birth weight and high birth weight infants are both at an increased risk to have type 2 diabetes among schoolchildren in Taiwan. Diabetes Care. 2003;26(2):343-8.

39 Cambuli VM, Incani M, Pilia S, Congiu T, Cavallo MG, Cossu E, et al. Oral glucose tolerance test in Italian overweight/obese children and adolescents results in a very high prevalence of impaired fasting glycaemia, but not of diabetes. Diabetes Metab Res Rev. 2009;25(6): 528-34.

40 Brufani C, Ciampalini P, Grossi A, Fiori R, Fintini D, Tozzi A, et al. Glucose tolerance status in 510 children and adolescents attending an obesity clinic in Central Italy. Pediatr Diabetes. 2010;11(1):47-54.

41 Aguayo A, Vela A, Aniel-Quiroga A, Blarduni E, Fernández C, Grau G, et al. Absence of diabetes mellitus type 2 in obese children and adolescents in the north of Spain. J Pediatr Endocrinol Metab. 2013;26(1-2):25-9.

42 Riste L, Khan F, Cruickshank K. High prevalence of type 2 diabetes in all ethnic groups, including Europeans, in a British inner city: relative poverty, history, inactivity, or $21 \mathrm{st}$ century Europe? Diabetes Care. 2001;24(8): 1377-83.
43 Neu A, Feldhahn L, Ehehalt S, Ziegler J, Rothe U, Rosenbauer J, et al. No change in type 2 diabetes prevalence in children and adolescents over 10 years: update of a populationbased survey in South Germany. Pediatr Diabetes. 2018;19(4):637-9.

44 Spanakis EK, Golden SH. Race/Ethnic difference in diabetes and diabetic complications. Curr Diab Rep. 2013;13(6):814-23.

45 Benchimol EI, Manuel DG, To T, Mack DR Nguyen GC, Gommerman JL, et al. Asthma, type 1 and type 2 diabetes mellitus, and inflammatory bowel disease amongst South Asian immigrants to Canada and their children: a population-based cohort study. PLoS One. 2015;10(4):e0123599.

46 Jabar F, Colatruglio S, Sellers E, Kroeker K, Wicklow B. The next generation cohort: a description of a cohort at high risk for childhood onset type 2 diabetes. J Dev Orig Health Dis. 2019;10(1):24-30.

47 Millar K, Dean HJ. Developmental origins of type 2 diabetes in aboriginal youth in Canada: it is more than diet and exercise. J Nutr Metab. 2012;2012:127452.

48 Mexico: Secretaria de Salud. Prevencion y Diagnostico de la Diabetes Mellitus tipo 2 en el paciente pediatrico en el primer nivel de atencion. 2015. Available from: www.cenetec salud.gob.mx [Accessed 2018 Mar 8].

49 Roden M. Diabetes Mellitus-Definition, Klassifikation und Diagnose. Wien Klin Wochenschr. 2016;128(S2):37-40.

50 Stadler M, Fröhlich-Reiterer E, Prager R. Typ 2 Diabetes Mellitus: Screening und Prävention. Wien Klin Wochenschr. 2016;128(S2): 41-4.

51 Zuckerman-Levin MN, Strich D, Shehadeh $\mathrm{N}$. Guidelines for treating diabetes in children. 2016. Available from: https://www.ima. org.il/userfiles/image/Ne58_ChildrenDiabitis.pdf [Accessed 2018 Jun].
52 Ministry of Health Malaysia. Clinical practice guidelines. Management of type 2 diabetes mellitus. 5th ed. 2015. Available from: http:// www.acadmed.org.my/index.cfm? \&amp; menuid=67 [Accessed 2018 Apr 16].

53 Dedov I, Shestakova M, Mayorov A. КЛИНИЧЕСКИЕ РЕКОМЕНДАЦИИ $\begin{array}{llllllllll} & \text { А } & Л & Г & О & \text { Р } & И & \text { Т } & \text { М } & \text { Ы }\end{array}$ С П Е Ц И А Л И $З$ И Р О В А Н Н О Й МЕДИЦИНСКОЙ ПОМОЩИБОЛЬНЫМ САХАРНЫМ ДИАБЕТОМ (Standards of specialized diabetes care). 9th ed. 2019.

54 National Institute for Health and Care Excellence. Diabetes (type 1 and type 2) in children and young people: diagnosis and management (ng18). 2015. Available from: https:// www.nice.org.uk/guidance/ng18 [Accessed 2018 Apr 16]

55 Das A, Kalra S. CDiC textbook of pediatric diabetes. New Delhi, India: Jaypee Brothers Medical Publishers; 2017.

56 Panagiotopoulos C, Panagiotopoulos C, Hadjiyannakis $\mathrm{S}$, Henderson M. Type 2 diabetes in children and ddolescents. Can J Diabetes. 2018;42(Suppl 1):S247-54.

57 Praveen PA, Madhu SV, Mohan V, Das S, Kakati S, Shah N, et al. Registry of Youth Onset Diabetes in India (YDR): rationale, recruitment, and current status. J Diabetes Sci Technol. 2016;10(5):1034-41.

58 Prasad AN. Type 2 diabetes mellitus in young need for early screening. Indian Pediatr. 2011; 48(9):683-8.

59 Nadeau KJ, Anderson BJ, Berg EG, Chiang JL, Chou H, Copeland KC, et al. Youth-onset type 2 diabetes consensus report: current status, challenges, and priorities. Diabetes Care. 2016;39(9): 1635-4.

60 Kyrou I, Tsigos C, Tsigos C, Mavrogianni C, Cardon G, Van Stappen V, et al. Sociodemographic and lifestyle-related risk factors for identifying vulnerable groups for type 2 diabetes: a narrative review with emphasis on data from Europe. BMC Endocr Disord. 2020; 20(S1):1-13. 